\title{
Lead and cadmium in conventional and organic carrots
}

\section{Abstract}

Toxic elements like lead and cadmium are considered harmful to human health. These elements do not have any useful function in an organism. They are known only for their negative actions, which can be tolerated by human body only in certain limits. Carrots may absorb these toxic elements from the soil they grow in. The presence of the contaminants depends mainly on the mode and site of cultivation, fertilizer, industrial infrastructure, level of transportation and roads around cultivation site or occurrence of municipal and agricultural waste nearby. The organic food is supposed to be healthier due to, among other things, less content of toxic substances, which results from more sustainable farming. The aim of this research was to determine the content of lead and cadmium in carrots from conventional and organic farming that were available on polish market.

The research had been conducted for two years. Both kinds of carrots had been purchased at the same time in different supermarkets in Poland. Altogether, 36 packages, both conventional and organic carrots, were collected. The samples of carrots were dried and then reduced to ashes in $480{ }^{\circ} \mathrm{C}$ within few hours. Then the residues were dissolved in $1 \mathrm{M}$ nitric acid and quantitatively transferred to measuring flasks, complemented with deionised water. The content of cadmium and lead was determined by application of electrothermal atomizer (graphite furnace) in iCE 3000 (Thermo Scientific, USA) spectrometer using adequate cathode lamps and Zeeman background correction. Wavelengths for analysis of lead and cadmium were $217 \mathrm{~nm}$ and $288.8 \mathrm{~nm}$ respectively.

The results show that there are statistically significant differences in the average content of lead and cadmium in conventional and organic carrots. The concentrations of lead in conventional and organic carrots were $0.0192 \mathrm{mg} \mathrm{kg}^{-1}$ and $0.0118 \mathrm{mg} \mathrm{kg}^{-1} \mathrm{respectively}$. The concentrations of cadmium in conventional and organic carrots were $0.0050 \mathrm{mg} \mathrm{kg}^{-1}$ and $0.0023 \mathrm{mg} \mathrm{kg}^{-1}$ respectively.

The research indicates that toxic elements like $\mathrm{Pb}$ and $\mathrm{Cd}$ are present in both types of carrots, but their amount is lower than permissible concentrations established by EU ordinance. The conducted experiments also showed that the content of $\mathrm{Pb}$ and $\mathrm{Cd}$ in organic carrots is lower than in the conventional ones. This may be resulted in the differences in farming.

\section{Conflict of Interest}

There is no conflict of interest. 